\title{
Angiotensin II receptor antagonist reduces urinary liver-type fatty acid-binding protein levels in patients with diabetic nephropathy and chronic renal failure
}

\author{
T. Nakamura $\cdot$ T. Sugaya $\cdot$ H. Koide
}

Received: 25 July 2006 / Accepted: 1 November 2006 / Published online: 15 December 2006

(C) Springer-Verlag 2006

To the Editor: The incidence of end-stage renal failure due to diabetic nephropathy has increased dramatically over the past 20 years. It is widely accepted that the rate of functional decline correlates with the severity of renal tubulointerstitial lesions. Previous studies have shown that renal function in patients with type 2 diabetes correlates better with tubulointerstitial changes than with glomerular pathology [1]. Further studies on tubulointerstitial injury in patients with diabetic nephropathy may provide additional insight into the pathogenesis of diabetic nephropathy and lead to the identification of therapeutic targets. Several factors play an important role in the progression of renal injury. Oxidative stress is both a cause and consequence of interstitial inflammation [2]. Tissue hypoxia resulting from angiotensin-induced vasoconstriction or from structural disruption of peritubular capillaries is a final common pathway in the development of tubulointerstitial fibrosis. Liver-type fatty acid-binding protein (L-FABP) is produced in the proximal tubules, where it plays a key role in fatty acid metabolism. Stresses to the proximal tubules tend to overload fatty acids in the cytoplasm and thereby damage tubules with the release of inflammatory factors. In this way, tubulointerstitial inflammation is provoked, and renal

\footnotetext{
T. Nakamura

Department of Medicine, Shinmatsudo Central General Hospital, Chiba, Japan

T. Sugaya

Research Unit for Organ Regeneration, Riken Kobe Institute,

Hyogo, Japan

H. Koide $(\bowtie)$

Department of Medicine, Koto Hospital,

6-8-5 Ojima, Koto-ku,

Tokyo 136-0072, Japan

e-mail: hkoide@koto-hospital.or.jp
}

function deteriorates over time. Urinary excretion of L-FABP increases with the deterioration of kidney function and is a useful clinical marker for monitoring chronic kidney disease [3]. We have reported that urinary L-FABP may be a useful clinical marker for type 2 diabetic nephropathy [4].

Several treatments have been shown to halt or retard the progression of diabetic nephropathy. Suppression of the renin-angiotensin system is currently the most widely used therapy in clinical practice [2]. Unique renoprotective properties of angiotensin II receptor antagonist, which are independent of blood pressure lowering but related to decreased oxidative stress and correction of chronic hypoxia, have been reported [5]. Telmisartan, a highly selective angiotensin II type I receptor antagonist, reduces blood pressure and proteinuria effectively and safely in patients with moderate or advanced-stage renal insufficiency due to various types of nephropathy [6]. Long-term administration of high doses of telmisartan seems to improve the efficacy of the drug to decrease proteinuria and slow progression to end-stage renal failure in nondiabetic hypertensive renal disease [7]. The aim of the present study was to determine whether telmisartan affects the urinary L-FABP level as a marker of proximal tubule injury in patients with type 2 diabetic nephropathy and renal insufficiency.

The subjects were 30 type 2 diabetic nephropathy patients with renal insufficiency (18 men, 12 women; mean age 52.0 years; mean serum creatinine $221.0 \mu \mathrm{mol} / \mathrm{l}$; mean systolic blood pressure $154 \mathrm{mmHg}$; mean diastolic blood pressure $96 \mathrm{mmHg}$ ) and 30 age-matched healthy subjects (18 men, 12 women; mean age 50.0 years; mean serum creatinine $79.6 \mu \mathrm{mol} / \mathrm{l}$; mean systolic blood pressure $118 \mathrm{mmHg}$; mean diastolic blood pressure $74 \mathrm{mmHg}$ ). Patients were randomly assigned to receive telmisartan at 
Table 1 Baseline patient characteristics and follow-up changes with telmisartan treatment

\begin{tabular}{|c|c|c|c|c|c|c|c|}
\hline & \multicolumn{3}{|c|}{ Telmisartan $40 \mathrm{mg} /$ day $(n=15)$} & \multicolumn{3}{|c|}{ Telmisartan $80 \mathrm{mg} /$ day $(n=15)$} & \multirow[t]{2}{*}{ Healthy subjects $(n=30)$} \\
\hline & Baseline & 6 months & 12 months & Baseline & 6 months & 12 months & \\
\hline Age (years) & $53.0 \pm 9.0$ & & & $51.0 \pm 8.0$ & & & $50.5 \pm 10.5$ \\
\hline Sex (male/female) & $9 / 6$ & & & $9 / 6$ & & & $18 / 12$ \\
\hline $\mathrm{SBP}(\mathrm{mmHg})$ & $156 \pm 18$ & $128 \pm 8^{b}$ & $126 \pm 8^{b}$ & $152 \pm 16$ & $122 \pm 6^{b}$ & $124 \pm 6^{\mathrm{b}}$ & $118 \pm 8$ \\
\hline DBP $(\mathrm{mmHg})$ & $98 \pm 8$ & $86 \pm 4^{\mathrm{b}}$ & $82 \pm 4^{\mathrm{b}}$ & $94 \pm 6$ & $82 \pm 4^{\mathrm{b}}$ & $80 \pm 4^{\mathrm{b}}$ & $74 \pm 4$ \\
\hline $\begin{array}{l}\text { Serum creatinine } \\
(\mu \mathrm{mol} / 1)\end{array}$ & $229.8 \pm 53.0$ & $238.7 \pm 61.9$ & $225.8 \pm 41.2$ & $212.2 \pm 35.4$ & $229.8 \pm 44.2$ & $238.7 \pm 53.0$ & $79.6 \pm 17.7$ \\
\hline eGFR $(\mathrm{ml} / \mathrm{s})$ & $0.70 \pm 0.17$ & $0.68 \pm 0.17$ & $0.67 \pm 0.13$ & $0.73 \pm 0.20$ & $0.71 \pm 0.17$ & $0.68 \pm 0.13$ & $1.83 \pm 0.18$ \\
\hline Proteinuria (g/day) & $2.2 \pm 1.2$ & $1.6 \pm 0.8^{\mathrm{a}}$ & $1.2 \pm 0.6^{\mathrm{b}}$ & $2.4 \pm 1.2$ & $1.0 \pm 0.6^{\mathrm{b}, \mathrm{d}}$ & $0.6 \pm 0.5^{\mathrm{c}, \mathrm{d}}$ & $0.1 \pm 0.1$ \\
\hline $\begin{array}{l}\text { Urinary L-FABP } \\
\left(\mu \mathrm{g} \mathrm{g}^{-1} \text { creatinine }^{-1}\right)\end{array}$ & $88 \pm 52$ & $64 \pm 44^{\mathrm{a}}$ & $48 \pm 30^{\mathrm{b}}$ & $92 \pm 74$ & $32 \pm 20^{\mathrm{b}, \mathrm{d}}$ & $20 \pm 14^{\mathrm{c}, \mathrm{d}}$ & $5.6 \pm 3.5$ \\
\hline
\end{tabular}

${ }^{\mathrm{a}} p<0.05,{ }^{\mathrm{b}} p<0.01,{ }^{\mathrm{c}} p<0.001$ versus before; ${ }^{\mathrm{d}} p<0.01$ for $40 \mathrm{mg}$ versus $80 \mathrm{mg}$

eGFR, estimated GFR; SBP, systolic blood pressure; DBP, diastolic blood pressure

$40 \mathrm{mg} /$ day $(n=15)$ or $80 \mathrm{mg} /$ day $(n=15)$ for 12 months. Treatment was blinded. Informed consent was obtained from each patient and control subjects. The study protocol was approved by the local ethics committee and the study was carried out in accordance with the Declaration of Helsinki as revised in 2000. Data are shown as mean \pm SD. Differences in values were tested by analysis of variance or Mann-Whitney $U$ test. A $p$ value of less than 0.05 was considered statistically significant.

The data including patient characteristics and followup results are shown in Table 1. Baseline patient characteristics, including blood pressure, estimated GFR, renal function, proteinuria and urinary L-FABP levels, were similar in the two groups. There were no differences between the telmisartan $40-\mathrm{mg}$ and $80-\mathrm{mg}$ groups in comparison with other antihypertensive agents or diuretics. Blood pressure control did not differ between groups during the follow-up period. The serum creatinine level and estimated GFR changed little in either group during the follow-up period. Telmisartan $40 \mathrm{mg}$ /day significantly reduced both proteinuria and urinary L-FABP after 6 months $(p<0.05)$ and after 12 months $(p<0.01)$, effects also achieved with telmisartan $80 \mathrm{mg} /$ day at $6(p<$ $0.01)$ and at 12 months $(p<0.001)$. Decreases in proteinuria and urinary L-FABP levels were significantly more pronounced in the $80-\mathrm{mg}$ group than in the $40-\mathrm{mg}$ group $(p<0.01)$.

L-FABP has been shown to be a novel clinical marker that can help predict and monitor the progression of renal disease [4]. Inhibition of the renin-angiotensin system plays a major part in management of type 2 diabetes patients with nephropathy. However, little is known about the effect of angiotensin II receptor antagonists on tubulointerstitial injuries in patients with diabetic nephropathy with renal insufficiency. The changes in urinary L-FABP were significantly correlated with the progression of renal disease and those in urinary protein excretion and urinary $N$-acetyl- $\beta$-D-glucosaminidase (NAG) activity were not, suggesting that urinary L-FABP is more sensitive than urinary protein or NAG in the monitoring of progression of chronic renal disease [3]. L-FABP is produced in the liver and the kidney (proximal tubules). It is possible that serum L-FABP derived from the liver influences urinary L-FABP. However, some investigators [8] have reported that serum L-FABP levels do not affect urinary L-FABP level, suggesting that the L-FABP measured in urine originates from renal proximal tubule cells.

These data suggest that telmisartan decreases proteinuria and the urinary L-FABP level in a dose-dependent manner that is independent of its blood pressure-lowering effect in diabetic nephropathy patients with renal insufficiency. Telmisartan may be effective in ameliorating tubulointerstitial injury in patients with type 2 diabetic nephropathy. Large-scale, multi-centre randomised studies should be conducted in the future.

Acknowledgements We thank K. Node, Department of Cardiovascular and Renal Medicine, Saga University Faculty of Medicine, for his helpful suggestions.

Duality of interest The authors have declared that no dualities of interest exist in connection with this study.

\section{References}

1. Phillips AO (2003) The role of renal proximal tubular cells in diabetic nephropathy. Curr Diab Rep 3:491-496

2. Rodriguez-Iturbe B, Johnson RJ, Herrera-Acosta J (2005) Tubulointerstitial damage and progression of renal failure. Kidney Int Suppl 99:S82-S86 
3. Kamijo A, Sugaya T, Hikawa A et al (2005) Clinical evaluation of urinary excretion of liver-type fatty acid binding protein as a marker for the monitoring of chronic kidney disease: a multicentered trial. J Lab Clin Med 145:125-133

4. Nakamura T, Sugaya T, Kawagoe Y, Ueda Y, Osada S, Koide H (2005) Effects of pitavastatin on urinary liver-type fatty acidbinding protein levels in patients with early diabetic nephropathy. Diabetes Care 28:2728-2732

5. Izuhara Y, Nangaku M, Inagi R et al (2005) Renoprotective properties of angiotensin receptor blockers beyond blood pressure lowering. J Am Soc Nephrol 16:3631-3641
6. Weinbegova O, Metelka R, Jymetal J, Konecny K, Kosatikova Z (2004) Telmisartan in the treatment of hypertension in patients with chronic renal insufficiency. Biomed Pap Med Fac Univ Palacky Olomouc Czech Repub 148:69-73

7. Aranda P, Segura J, Ruilope LM et al (2005) Long-term renoprotective effects of standard versus high doses of telmisartan in hypertensive nondiabetic nephropathies. Am J Kidney Dis 46:1074-1079

8. Kamijo A, Sugaya T, Hikawa A et al (2006) Urinary liver-type fatty acid binding protein as a useful biomarker in chronic kidney disease. Mol Cell Biochem 284:175-182 